\title{
OS TESTES DE APTIDÃO FÍSICA NA EDUCAÇÃO FÍSICA: DA JUS- TIÇA COMO EQUIDADE AO DIREITO À EDUCAÇÃO' ${ }^{1}$
}

\author{
Guilherme Gonçalves Baptista \\ Universidade Federal do Rio de Janeiro, Rio de Janeiro, Rio de Janeiro, Brasil \\ Juliana Gonçalves Baptista \\ Universidade Federal do Rio de Janeiro, Rio de Janeiro, Rio de Janeiro, Brasil
}

\begin{abstract}
Resumo
É justo limitar a entrada de alunos em cursos de Educação Física devido ao insucesso nos testes físicos? O presente ensaio apresenta reflexões iniciais sobre a legitimidade e as limitações da exigência dos testes de habilidade específica para o ingresso discente nos cursos superiores em Educação Física, trazendo à baila questões sobre justiça e direito à educação. A partir da teoria de justiça rawlsiana, os testes foram mobilizados para problematizar as condições mínimas necessárias para ingresso discente e as próprias identidades profissionais em torno da Educação Física. Notou-se que a exigência de competências mínimas colidia com o processo plural de construção identitária da área e servia, de certo modo, como um limitador da própria condição humana: o direito à educação.
\end{abstract}

Palavras-chave: Educação Física. Métodos de avaliação. Aptidão física. Equidade.

\section{Introdução}

Muitos trabalhos alinhados à historiografia da Educação Física, entre eles o de Soares (2012), assinalam que os discursos relativos à abordagem técnica e do rendimento eram frequentes na área ao longo de sua história no Brasil, com resquícios (ou mesmo predomínio) até os dias atuais (GÓIS JUNIOR; LOVISOLO, 2003). Uma das possíveis marcas da valorização dessas abordagens era a exigência da realização de testes de Aptidão Física ou de habilidade específica, como também eram chamados, para o ingresso de alunos nos cursos superiores de Educação Física nacional (BAPTISTA, 2015).

Esses testes, de modo geral, constituíram parte do processo de vestibular destinado aos interessados em ingressar no curso superior de Educação Física no Brasil até início dos anos 1990. Segundo informa Camões (1988), os testes de Aptidão Física consistiam em uma bateria de exercícios físicos que serviam como meios para selecionar os candidatos que apresentavam maior potencial para a aprendizagem, sucesso acadêmico e boa formação profissional na área.

De acordo com Oliveira (1991), esses testes ocorrem desde a abertura da Escola Nacional de Educação Física e Desportos (ENEFD) da Universidade do Brasil em 1939 e, desde então, foram vistos como um consenso pedagógico tradicional na área. Vale lembrar que a ENEFD foi a primeira instituição civil de formação em Educação Física no Brasil ligada a uma universidade.

Apesar de habitual a exigência dos testes de habilidades específicas pelos cursos superiores de Educação Física no Brasil até meados dos anos 1990 (ZINN, 1988), a seleção de

\footnotetext{
${ }^{1} \mathrm{O}$ presente trabalho não contou com apoio financeiro de nenhuma natureza para sua realização.
} 
quais comporiam a bateria de exercícios não era consenso na área. Teixeira (1984) afirma que a validade dos testes exigidos era discutida constantemente, pois se poderiam eliminar bons candidatos por uma insuficiência do processo de avaliação.

Por outro lado, observa-se que não se questionava a validade dos testes como meio viável para a seleção de candidatos à Educação Física, limitando-se ao debate apenas de quais exercícios seriam mobilizados para tal efeito. Nesse sentido, nota-se um possível consenso entre os agentes da área de que a avaliação de técnicas corporais atestaria a capacidade do aluno em se tornar um bom professor e, consequentemente, selecionaria os alunos com "vocação" para a profissão. É importante sublinhar que essa hipótese foi rejeitada por alguns estudos, tais como o de Camões (1988) e Zinn (1988).

Essa exigência, porém, não foi restrita à Educação Física ao longo dos anos, sendo os testes de habilidades específicas ainda presentes para outros cursos, como Arquitetura, Artes Cênicas, Música, Dança, entre outros. No entanto, no caso da Educação Física, a ideia de que existam habilidades a priori que são essenciais para permitir alguém vir a ser professor ainda é um ponto de debate. Decerto, atualmente, essa ideia não é mais um consenso pedagógico, como defendeu Oliveira (1991) em momento anterior. Contudo, não se nega que ainda há defensores e críticos desses tipos de teste.

Afinal, é legítimo impedir a entrada de alunos devido a testes de Aptidão Física que supostamente preveriam parâmetros básicos para o sucesso acadêmico ou que atestariam a vocação para a área? Ou, ainda, é justo que o sucesso ou fracasso em poucos testes determine a carreira de um indivíduo que deseja ser professor? Ao considerar que a educação é um dos principais meios de acesso a posições ocupacionais e de renda hierarquicamente superiores (RIBEIRO, 2011) e que, em particular, a educação superior tem forte impacto nessa ocupação no mercado de trabalho (CARVALHO; WALTEMBERG, 2012), deve-se problematizar a legitimidade e as limitações dos testes de habilidade específica como barreiras limitadoras do acesso ao ensino superior.

Diante disso, esses testes, tão comuns para o ingresso discente nos cursos superiores de Educação Física até início dos anos 1990, foram tratados como dispositivos para problematizar questões sobre princípios de justiça, sobretudo sob as luzes teóricas de John Rawls (2000) e o direito à educação. Com isso, o presente ensaio apresenta reflexões iniciais sobre a legitimidade e as limitações da exigência dos testes de habilidade específica no campo da Educação Física.

\section{A teoria de justiça e acesso à educação superior: questões sobre os testes de habilidade específica}

Vários autores já despenderam esforços para responder o que seria justiça acadêmica/escolar, todavia, esse ponto ainda é alvo de discussões. Segundo Dubet (2004), a definição do que seria uma escola justa é das mais complexas e, ao mesmo tempo, ambíguas, uma vez que se pode definir justiça de diferentes maneiras. Para este autor, o problema de definir o que seria justiça escolar ocorre por ser uma combinação de escolhas e respostas necessariamente limitadas acerca de concepções e princípios de justiça.

A partir desse entendimento de combinação de escolhas e respostas assumidamente limitadas, dedicou-se aqui à discussão da justiça, sob as luzes da teoria de Rawls (2000) em torno dos testes de Aptidão Física. Embora formulada por meio de situações hipotéticas e ahistóricas, a teoria de justiça rawlsiana contribui para analisar algumas nuanças dessa exigência. Logicamente, não se pretendeu esgotar ou mesmo definir os princípios de justiça que devam pautar a problemática em voga, mas trazer à baila questões iniciais a serem debatidas sobre esses tipos de condicionantes. 
Em busca de apresentar uma concepção de justiça que generalize e abstraia a teoria de contrato social, Rawls (2000) defende o conceito de justiça como equidade. Para ele, a ideia central de uma concepção de justiça deveria se constituir no momento em que os princípios para a estrutura básica da sociedade fossem objeto de consenso original dos indivíduos. Nas palavras de Rawls (2000, p. 12), uma sociedade justa seria aquela regida por princípios que "pessoas livres e racionais, preocupadas em promover seus próprios interesses, aceitariam numa posição inicial de igualdade como definidores dos termos fundamentais de sua associação".

Desse modo, para alcançar esse consenso original, Rawls (2000) afirma que os princípios estruturantes que regeriam as instituições sociais ${ }^{2}$ deveriam ser criados a partir de um pressuposto normativo denominado "véu da ignorância". Tal pressuposto normativo estaria presente no instante em que os sujeitos estivessem em suas posições originais, ou seja, posição em que os atores estão desprovidos de qualquer conhecimento sobre seu lugar na sociedade, suas habilidades naturais, seus bens ou coisas semelhantes que informassem sua situação terrena.

Portanto, o figurado consenso original seria fruto do momento em que os sujeitos em suas posições originais decidiriam tudo aquilo que seria considerado justo ou injusto, por meio dessa hipotética liberdade equitativa, sendo tratadas também as possibilidades de desigualdades no interior dessa sociedade. Em outras palavras, o consenso original ocorreria por meio dessa hipotética neutralidade a partir do "marco zero" dos indivíduos. Essas definições em conjunto subsidiariam os princípios da justiça, regulando todos os acordos posteriores, "uma vez que todos estão numa situação semelhante e ninguém pode designar os princípios para favorecer sua situação particular" (RAWLS, 2000, p. 12). É justamente esse hipotético retorno à posição original sob o véu da ignorância que subsidiará a sistematização dos princípios de justiça como equidade na teoria ralwsiana, como resultado de um consenso ou ajuste equitativo.

Ao avançar nas discussões, Rawls (2000) sustenta dois princípios estruturantes básicos em sua ideia de justiça, embora reconheça a dificuldade dessas escolhas. São eles: 1) a igualdade na instituição de deveres e direitos básicos; e 2) as desigualdades econômicas e sociais são justas somente se acarretam benefícios compensatórios para cada um, e, sobretudo, para os menos favorecidos da sociedade ${ }^{3}$.

Ao comentar esses princípios, Morche e Neves (2011) afirmam que o primeiro exprime que a restrição de liberdade só é possível se vier para reforçar a liberdade compartilhada por todos ou se for aceita por aqueles que possuem uma menor liberdade. Já o segundo princípio explicita a ideia de que as desigualdades são justas na medida em que são ajustadas para garantir condições de igualdade de oportunidades a todos.

Portanto, com base na teoria de Rawls (2000), a justiça como equidade na educação superior fundamentar-se-ia no momento que houvesse uma igualdade de oportunidades e de permanência a todos que desejassem e tivessem condições de cursar esse nível de ensino. Em um mesmo sentido, Morche e Neves (2011) afirmam que o sistema educacional seria justo quando garantisse que os cidadãos tivessem oportunidades adequadas de acesso e permanência, sem quaisquer tipos de discriminação que determinassem e diferenciassem as oportunidades de acesso à educação superior. Embora seja uma teoria não utilitarista, compreende-se que

\footnotetext{
${ }^{2}$ Cumpre ressaltar que, para Rawls (2000), as instituições sociais seriam responsáveis por intermediar as relações sociais entre as pessoas, sendo a justiça tratada como a primeira virtude das instituições sociais na teoria rawlsiana.

${ }^{3}$ Cabe acentuar que, segundo Rawls (2000), o princípio de utilidade seria incompatível com uma sociedade na qual as pessoas fossem vistas como iguais, já que não concordariam com um princípio que poderia "exigir para algumas expectativas de vida inferiores, simplesmente por causa de uma soma maior de vantagens desfrutadas por outros" (p. 15).
} 
seu quadro intelectual possibilita novas reflexões com o intuito de minimizar as desigualdades.

Com base em tais premissas, questiona-se até que ponto a exigência dos testes de habilidade específica (ou qualquer outra) considera ou procura garantir a igualdade de oportunidades para todos. Além disso, como se pode dizer que os possíveis candidatos, sejam portadores de necessidades especiais ou não, são sujeitos de direitos se, ao mesmo tempo, são excluídos precocemente da avaliação pela distribuição do conhecimento pertencente à área?

Essas questões, logicamente, não se resumem somente ao reconhecimento das diferenças, embora seja um ponto imprescindível para essa análise, uma vez que o reconhecimento é uma necessidade humana vital (FRASER, 2001). Para Carvalho e Waltemberg (2012), quando existe sub-representação por parte de um grupo no acesso a um serviço ou vantagem presencia-se um problema de desigualdade de oportunidades, já que, em maior parte, a dificuldade de obter acesso ao serviço ou vantagem é causada por circunstâncias desfavoráveis.

Contudo, outro ponto fundamental recorrentemente convocado pelos defensores dos testes é a defesa da garantia das competências/condições mínimas para o exercício da profissão. Tal discurso, em termos utilitários, é satisfatório na medida em que os processos seletivos requerem, obviamente, a escolha dos mais adequados para a subsequente função e cada cargo/profissão requer uma série de conhecimentos.

No que diz respeito às competências mínimas, Dubet (2004) também reconhece a legitimidade desse argumento ao defender que um sistema justo deva garantir limites mínimos. $\mathrm{O}$ autor complementa: "o sistema justo, ou menos injusto, não é o que reduz as desigualdades entre os melhores e os mais fracos, mas o que garante aquisições e competências vistas como elementares [...]" (DUBET, 2004, p. 547) a todos. Para Rawls (2000), equidade seria admitir um sistema que não prive nenhum indivíduo de ser percebido como apto à cooperação social, contemplando também o interesse de cada um.

Logo, os testes de habilidade específica surgem como importantes indícios para problematizar quais seriam as condições mínimas necessárias para ingresso no curso de formação da área e, com isso, as próprias identidades profissionais em torno do professor de Educação Física. Compreende-se que as identidades são formadas e transformadas por um processo contínuo e não linear, por isso não podem ser tratadas de maneira única (DUBAR, 1997).

Primeiramente, no que diz respeito à construção das identidades na Educação Física brasileira, Figueiredo (2010) expõe que as mudanças epistemológicas da área, sobretudo nos anos 1970 e 1980, colocaram em questão seu próprio objeto de estudo e de ensino. Deste modo, essas mudanças operam como um agente provocador de rupturas e mudanças na (re)construção de formas identitárias desse professor até os dias atuais. Para Oliveira (1994), esse período é assinalado como um momento de aprofundamento sobre as discussões de valores e normas que eram produzidas a partir das práticas corporais, alterando estruturas paradigmáticas na área.

Baptista (2015) ilustra parte desse processo de distinção identitária na formação de professores da Escola de Educação Física e Desportos da Universidade Federal do Rio de Janeiro (EEFD/UFRJ) ao avaliar a reformulação curricular ocorrida nos anos 1980. Conforme o autor:

A partir dessas mudanças curriculares, observa-se que o próprio perfil profissional desejado, a princípio, está em processo de modificação ou, melhor, de ampliação [...] Busca-se um profissional mais embasado cientificamente, através dos saberes biomédicos, e preocupado com o processo de ensino-aprendizagem a partir da valorização dos saberes pedagógicos, além do profissional especialista em determinados desportos (BAPTISTA, 2015, p. 90). 
É relevante sublinhar que, apesar das mudanças ocorridas na Educação Física, a vinculação entre a área e os esportes ao longo dos anos ainda é uma das principais marcas identitárias do curso (FIGUEIREDO, 2004). O gosto pelo esporte parece ser, portanto, uma das primeiras formas de seleção para a área, evidenciando uma cultura esportiva à qual se deve estar inserida.

Hodiernamente, o processo de construção de identidade social do professor de Educação Física tornou-se acentuadamente ambíguo e múltiplo ao valorizar outros quesitos presentes no que denominam de cultura corporal - saberes sobre as diferentes manifestações e linguagens corporais produzidas pelos seres humanos em sua história (SOARES et al, 1992). Assim, há uma ampliação das preocupações da área para além da técnica e do rendimento atrelados ao esporte, apesar dessas normas e valores permanecerem apreciados.

Consonante com a multiplicidade de quesitos e saberes presentes, as reformulações do currículo, ao longo da história, reforçam a não linearidade do constante processo de formação identitária. Nesse sentido, as modificações e disputas de legitimidade dos diferentes currículos avigoram a ocorrência de disputas internas de que tipo de profissional deseja se formar. Como, por exemplo, nos debates proferidos a partir da criação do curso de bacharelado em Educação Física, em 1987. Segundo Anderáos (2005), a criação desse curso deu-se no intuito de suprimir as defasagens da formação do professor licenciado para as necessidades da sociedade. Agregando, ainda, as resoluções de 2002 e 2004, houve uma demarcação da atuação do licenciado nas escolas e dos bacharéis no ambiente não escolar, o que gerou, e ainda gera, disputas de legitimidade dessa divisão.

Diversos autores, como Ilha (2010), acreditam que tal divisão permite uma maior especialização e qualificação em um desses campos. Porém, a referida divisão nunca foi consenso. Ela sofreu, e ainda sofre diversas críticas por "dicotomizar os conhecimentos próprios da área" (ILHA, 2010, p. 34). Não é à toa que atualmente diversas universidades estão reavaliando o currículo dos dois cursos no sentido de reunificar a área. Tal fato coloca a tona a constante disputa de quais saberes são essenciais na formação desse profissional.

No entanto, como é possível atualmente englobar as mais diferentes expressões e linguagens corporais por meio dos testes em um curso tão abrangente no que tange ao seu objeto de estudo? Ou, ainda, como definir as competências mínimas numa área tão vasta e distinta em relação à atuação do professor de Educação Física?

Com o intuito apenas de ilustrar alguns dos testes exigidos, observa-se que a bateria de exercícios na EEFD/UFRJ consistia, na década de 1980 até sua extinção no início dos anos 1990, nos seguintes testes: barra, abdominal, salto em extensão, voleibol; basquetebol; futebol (somente homens); saltos sucessivos sobre corda (somente mulheres); natação; e teste de Cooper (O GLOBO, 1980). Tais testes valorizavam, sobretudo, atividades consonantes à cultura esportiva sob a forma do desempenho e resultado, o que evidencia a técnica esportiva como condição central e barreira educacional para a entrada do futuro professor de Educação Física nesse período. Em razão de terem sido as habilidades motoras exigidas, tais saberes podem ser vistos como as condições mínimas para o ingresso discente na Educação Física.

Nesse ínterim, o praticante de atividades esportivas, seja atleta ou não, surgia possivelmente como modelo de aluno para o curso. Já os que não detinham esse capital (BOURDIEU, 2011 $)^{4}$, nem mesmo minimamente, estariam marginalizados dessa oportunidade de ingresso. Cabe ressaltar, novamente, que a discussão sobre quais eram os testes e a problematização da ideia presente nessas exigências de que "saber fazer corresponde a saber ensinar" não são tão relevantes aqui quanto no debate sobre a legitimidade e as limitações dessa co-

\footnotetext{
${ }^{4}$ Conforme definição de Bourdieu (2011), capital é a representação de um poder sobre determinado campo em dado momento.
} 
brança frente a sua busca de alinhamento ao conceito de justiça como equidade, sendo os testes descritos apenas como exemplos para fomentar o debate atual.

Nesse sentido, exaltam-se dois pontos: os saberes mobilizados (problemática em qualquer avaliação, seja de parâmetros motores ou não) para os testes e o ambiente universitário como espaço de formação e de combate às desigualdades de oportunidades. Sobre a primeira questão, embora seja apenas ilustrativa a lista dos testes exigidos na EEFD/UFRJ para a discussão, observa-se que a maioria dos testes cobrados eram expressões do campo ginástico e esportivo, certamente marcados pela forte influência europeia na construção da Educação Física no Brasil e do destaque obtido pelo fenômeno esportivo em todo o mundo (SOARES, 2012). Tais cobranças, muitas vezes, eram inclusive sustentadas por discursos reacionários alinhados à tese da ameaça (HIRSCHMAN, 1992) ${ }^{5}$, pois salientavam que a abertura para outros perfis de alunos colocaria em perigo a própria identidade do professor de Educação Física como agente do campo esportivo e ginástico. Uma das grandes ameaças que constantemente eram convocadas era o risco de teorizar demais uma profissão essencialmente voltada para a intervenção prática.

Porém, como visto, o campo de saberes de um professor de Educação Física não se limita ao campo desportivo nem ao ginástico, apesar de historicamente serem as práticas exigidas nesses testes. Há inúmeros saberes a serem explorados sobre a cultura corporal - expressão mais comumente utilizada nos anos 1980 -, sendo os do campo desportivo e ginástico apenas dois deles. É importante ressaltar que esse entendimento acerca dos campos de saberes da área e seus objetos de estudo avançaram, sobretudo, nas últimas duas décadas, sendo necessário evitar um olhar anacrônico para analisar a discussão da exigência de testes de habilidade específica hoje em dia.

Afinal, por que as práticas (saberes) esportivas e ginásticas foram selecionadas como únicas formas de manifestações corporais para a entrada dos alunos? Os próprios testes, assim, já definiam arbitrariamente a linguagem esportiva e ginástica para o futuro professor de Educação Física e desvalorizavam todas as outras expressões da cultura corporal, como, por exemplo, das lutas, das brincadeiras infantis, das danças folclóricas etc. Essas diferenças evidenciam uma desigualdade de oportunidades aos alunos interessados em cursar Educação Física nesses outros campos de atuação, afastando-se do sentido de justiça como equidade. Longe de ser uma particularidade dos testes de habilidade específica, essa seleção é própria de todo processo de avaliação: selecionam-se alguns conhecimentos e excluem tantos outros. Porém, por que manter mais um mecanismo fomentador da desigualdade e tão limitador do próprio campo de atuação profissional da Educação Física?

Além disso, em relação à exigência de habilidades motoras associadas ao esporte, por que razão tais saberes, que eram vistos como essenciais, são cobrados anteriormente e não ao final do curso? A resposta mais comum para essa questão no período de vigência dos testes, como apresentou Zinn (1988), era que a seleção de alunos com nível de habilidade motora adequada seria benéfica, pois seria uma exigência em muitas disciplinas ao longo do curso. Nota-se, novamente, que o referido discurso em torno dos testes privilegiava certo tipo de saber em detrimento de outros, pois havia inúmeros outros saberes para o processo de formação de professores "esquecidos". É digno de nota, também, que muitos dos testes, como o Teste de Cooper, exigiam qualidades que podiam ser temporárias e, por isso, não atestariam as características exigidas de maneira fidedigna.

Esse cenário evidencia, igualmente, o distanciamento do entendimento de justiça como equidade, formulado por Rawls (2000), ao desconsiderar dentro do curso outras formas de atuação social e também o próprio interesse de cada indivíduo. Aliás, os estudos acerca do

\footnotetext{
${ }^{5}$ Segundo afirma Hirschman (1992), a tese da ameaça é um dos traços marcantes da retórica considerada reacionária. Essa tese assevera que a mudança proposta acarreta consequências ou custos inaceitáveis de um ou outro tipo, embora essa alteração possa ser desejável em si.
} 
rendimento dos alunos ao longo do curso, como de Camões (1988), já revogavam a ideia causal entre os resultados dos testes e o índice de aproveitamento acadêmico dos alunos. Todavia, mesmo esses saberes sendo tratados como importantes, o que já foi alvo de debates, a capacidade de aprendizado mínimo deles não é considerada totalmente inata ou apenas retrato de um dom. Ou seja, esses saberes podem ser desenvolvidos durante o curso, pois são potencialidades humanas.

Além do mais, pela consequência fundamental e primeira do fato de nos tornarmos humanos pela incorporação de saberes legados, Charlot (2013) alerta que o direito à educação é uma condição para ser humano. Segundo as palavras do autor: "Não existe ser humano em si; por condição, o ser humano é certa realização social e cultural da humanidade [...] que sempre fica aberta" (CHARLOT, 2013, p. 170). Desse modo, em meio à precariedade das condições do ensino básico na Educação Física escolar ${ }^{6}$ e com a restrição das práticas corporais em outros ambientes, por exemplo, por questões de violência ou até mesmo econômicas, é justo limitar o acesso de indivíduos por conta de saberes negados, muitas vezes, pela própria sociedade?

Desta maneira, a exigência de saberes, muitas vezes, negados anteriormente e possíveis de serem adquiridos no espaço de formação colide com a busca da justiça como equidade aqui em voga ao desconsiderar a ideia de igualdade de oportunidades e a condição de "vir a ser" que define o ser humano. Diante disso, outra questão surge: é papel da universidade, até mesmo da escola, minimizar desigualdades em outros campos sociais?

Nessa linha, corrobora-se com Nóvoa (1999), quando afirma que a escola não pode colmatar a ausência de outras instituições sociais e familiares no processo de educação. No entanto, seja qual for o ambiente de ensino, seja escolar ou universitário, como instância democrática, deve ter como norte o combate a quaisquer tipos de discriminação e desigualdades, sejam em seu processo seletivo ou no decorrer do curso, recusando-se a fomentar tais disparidades. As instituições educacionais não podem ser responsabilizadas pelos demais problemas sociais, entretanto, não se pode pensar numa prática equitativa sem considerar tais injustiças.

Assim, a discussão sobre o ambiente universitário como espaço de formação e de combate às desigualdades de oportunidades torna-se imprescindível em busca de uma seleção mais equitativa. Não porque esses testes são mais ou menos justos do que as provas de vestibular hoje em dia, mas porque o ambiente educacional deve tentar minimizar tais desigualdades com as limitadas armas que lhes são possíveis. Pois ao subsidiar uma avaliação desprovida de sentido crítico e de justiça como equidade, a faculdade aproxima-se de uma espécie de má fé institucional, termo usado por Souza (2011) para apontar a estigmação de alunos por parte dos agentes escolares sem considerar as disposições dotadas por eles para alcançar o sucesso escolar.

Soma-se a isso o fato de que os testes de Aptidão Física estimulam a criação de estigmas corporais em torno do corpo "perfeito", hábil e performático, e "desviante". Tais estigmas fomentam ideias preconceituosas que muitas vezes não são problematizadas ao longo do curso de Educação Física. Conforme Goellner e Silva (2012), contemporaneamente, a neoeugenia, camuflada de ciência, defende o discurso da limpeza, do vigor, da potência e do espetáculo corporal em nome de antigos valores preconceituosos da eugenia, tais como: melhoria de raça, extirpação de vícios e doenças sociais.

\footnotetext{
${ }^{6}$ Muitas críticas eram feitas às práticas docentes na Educação Física escolar, sobretudo nos anos 1960 e 1970 , como destaca Taborda de Oliveira (2003). Segundo o autor, havia o discurso da necessidade de uma "maior padronização da formação inicial de Educação Física e o combate à incúria que grassava nas práticas escolares naquele período" (OLIVEIRA, 2003, p. 158). Cabe destacar, ainda, que várias dessas críticas persistem até os dias atuais.
} 
Ademais, consonante com as ideias de Luge e Silva (2013, p. 229), compreende-se que:

\begin{abstract}
O processo de formação de docentes, das mais diversas profissões, é contínuo, sendo o curso de graduação apenas uma "formação inicial" que possibilita a construção de habilidades mínimas para o exercício da profissão. Nos formamos enquanto escrevemos esse texto e no momento que essas linhas são lidas já não somos os mesmos, e, esperamos, que quem leia essas palavras também, de alguma maneira, mude. A compreensão que o processo de formação humana é um "vir a ser" [...] choca-se com qualquer concepção de formação docente que negue a chance de indivíduos cursarem licenciaturas em geral.
\end{abstract}

\title{
Considerações finais
}

Se os testes de Aptidão Física já não são tão comuns ou mesmo inexistentes no processo de ingresso discente para os cursos de Educação Física no Brasil, o mesmo não se pode dizer sobre as suas marcas no ideário de alguns professores universitários que recorrentemente reclamam da falta de preparo (motor?) dos alunos. Com pano de fundo do entendimento de justiça e direito à educação, este ensaio procurou trazer à baila reflexões iniciais sobre a legitimidade e as limitações desses testes, uma vez que suas vozes, embora de forma inibida e naturalizada nos discursos, ainda ecoam na formação de professores na área.

Em nome da busca da justiça como equidade aqui delineada, notou-se que a exigência de competências mínimas, embora razoável em quaisquer processos avaliativos, colidia com o próprio processo de construção identitária da Educação Física. Esse processo tornou-se ambíguo e múltiplo a partir das transformações que acometeram a área, sobretudo nos anos 1970 e 1980. Com isso, os testes de habilidade específica não correspondiam aos saberes plurais da área e, assim, tratava-se com desigualdade aqueles que ensejavam uma vaga nos cursos superiores de Educação Física.

Ademais, deve-se considerar que a seleção dos saberes mobilizados não é particularidade desse tipo de testes. No entanto, compreende-se que os testes, de certo modo, serviram como um limitador da própria condição humana: o direito à educação. Apesar de admitir que as competências mínimas sejam exigidas para as funções, tais competências (que são sempre problemáticas elencá-las) por vezes condicionam a entrada no ensino superior a disposições que foram negadas pela própria sociedade aos alunos. Portanto, crê-se que qualquer instituição escolar como meio democrático deva considerar tais injustiças. Não com o propósito de reparar todas as desigualdades sociais, mas com intuito de não fomentá-las.

Logicamente, sabe-se da limitação desse ensaio em dar soluções para os dilemas que envolvem a exigência dos testes de Aptidão Física na Educação Física e reconhece-se que se ofereceram mais inquietações do que respostas. Todavia, espera-se que essa reflexão inicial subsidie novos olhares necessários acerca dessa exigência. Por fim, entende-se, também, a necessidade de mais estudos sobre uma possível consonância entre os argumentos em favor da exigência dos testes de Aptidão Física e a presença de discursos reacionários em torno deles, mobilizados para conservar relações desiguais de poder no campo da Educação Física.

\section{THE PHYSICAL FITNESS TESTS IN PHYSICAL EDUCATION: FROM JUSTICE AS EQUITY TO THE RIGHT TO EDUCATION}

\begin{abstract}
Is it fair to limit the students admission in Physical Education courses due to unsuccess fulness in the physical fitness tests? This paper presents initial reflections on the legitimacy and
\end{abstract}


limits of the requirement of specific skill tests for student admission in Physical Education university courses, bringing up questions about justice and right to education. Based on Rawls' theory of justice, the tests were used to problematize the minimum necessary conditions for student admission and their own professional identities of Physical Education. It was noted that the requirement of minimum competencies was contrary to plural process of identity construction in the field, and it served, in a sense, as a restrictive action of the own human condition: the right to education.

Keywords: Physical Education. Evaluation methods. Physical fitness. Equity.

\section{LAS PRUEBAS DE APTITUD FÍSICAEN LA EDUCACIÓN FÍSICA: DE LA JUSTI- CIA COMO EQUIDAD AL DERECHO DE LA EDUCACIÓN}

Resumen: ¿Es justo limitar la entrada de alumnos a cursos de Educación Física debido al fracaso en las pruebas de habilidades físicas? El artículo presenta reflexiones iniciales sobre la legitimidad y los límites de la exigencia de pruebas de habilidades específicas para la admisión discente a los cursos de Educación Física, colocando en tela de juicio interrogaciones sobre justicia y el derecho a la educación. A partir de la teoría de justicia rawlsiana, se movilizaron las pruebas de habilidades físicas para discutir las condiciones mínimas necesarias para la admisión discente y las propias identidades profesionales acerca de la Educación Física. Se observó que la exigencia de habilidades mínimas chocó con el proceso plural de construcción de identidad del área y se usan, en cierto sentido, como un limitador de la condición humana: el derecho a la educación.

Palabras claves: Educación Física. Métodos de evaluación. Aptitud física. Equidad.

\section{Referências}

ANDERÁOS, M. A reorganização na formação profissional em educação física no Brasil: aspectos históricos significativos. 2005. 236f. Tese (Doutorado em Educação Física) Faculdade de Educação Física, Universidade Estadual de Campinas, Campinas, São Paulo, 2005.

BAPTISTA, G. G. A formação de professores na Escola de Educação Física e Desportos de 1979 a 1985: a educação do corpo e os territórios de diálogo. 2015. 168f. Dissertação (Mestrado em Educação Física) - Escola de Educação Física e Desportos, Universidade Federal do Rio de Janeiro, Rio de Janeiro, 2015.

BOURDIEU, P. O poder simbólico. Tradução Fernando Tomaz. 15. ed. Rio de Janeiro: Bertrand Brasil, 2011.

CAMÕES, J. C. O índice de aproveitamento acadêmico e sua correlação com o teste de habilidade específica. 1988. 142f. Dissertação (Mestrado em Educação Física) - Escola de Educação Física e Desportos, Universidade Federal do Rio de Janeiro, Rio de Janeiro, 1988.

CARVALHO, M. M.; WALTEMBERG, F. Cotas aumentam a diversidade dos estudantes sem comprometer o desempenho? Revista Sinais Sociais, Jacarepaguá, Rio de Janeiro, v. 7, n. 20, p. 36-77, 2012.

CHARLOT, B. Da relação com o saber às práticas educativas. São Paulo: Cortez, 2013. 
DUBAR, C. A socialização: construção das identidades sociais e profissionais. Tradução Anette Pierrette R. Botelho e Estela Pinto R. Lamas. Portugal: Porto Editora, 1997.

DUBET, F. O que é uma escola justa? Cadernos de Pesquisa, São Paulo, v. 34, n. 123, p. 539-555, 2004.

FIGUEIREDO, Z. C. C. Formação docente em Educação Física: experiências sociais e relação com o saber. Movimento, Porto Alegre, v. 10, n. 1, p. 89-111, 2004.

Experiências profissionais, identidades e formação docente em educação física. Revista Portuguesa de Educação, Portugal, v. 23, n. 2, p. 153-171, 2010.

FRASER, N. Da redistribuição ao reconhecimento? Dilemas da justiça na era pós-socialista. In: SOUZA, J. (Org.). Democracia hoje: novos desafios para a teoria democrática contemporânea. Brasília: EDUnB, 2001. p. 245-282.

GOELLNER, S. V.; SILVA, A. L. S. Biotecnologia e neoeugenia - olhares a partir do esporte e da cultura fitness. In: COUTO, E.; GOELLNER, S. V. (Org.). O triunfo do corpo: polêmicas contemporâneas. Petrópolis, RJ: Vozes, 2012. p. 187-210.

GÓIS JUNIOR, E.; LOVISOLO, H. R. Descontinuidades e continuidades do movimento higienista no Brasil. Revista Brasileira de Ciências do Esporte, Campinas, São Paulo, v. 25, n. 1, p. 41-54, 2003.

HIRSCHMAN, A. O. A retórica da intransigência: perversidade, futilidade, ameaça. Tradução Tomás Rosa Bueno. São Paulo: Companhia de Letras, 1992.

ILHA, F. O curso de licenciatura em Educação Física e os desafios da formação profissional: o processo de ensinar e aprender a docência. 2010. 129f. Dissertação (Mestrado em Educação) - Centro de Educação, Universidade Federal de Santa Maria, Santa Maria, Rio Grande do Sul, 2010.

LUGE, V.; SILVA, I. S. O Teste de Habilidade Específica enquanto cerceador do acesso à licenciatura em Artes Visuais: Um estudo de caso na UFRR. Revista Digital do LAV, Santa Maria, Rio Grande do Sul, ano VI, n. 11, p. 221-231, 2013.

MORCHE, B.; NEVES, C. E. B. Políticas de inclusão social na Educação Superior brasileira: as políticas afirmativas e o ProUni. In: XXVIII Congresso Internacional da ALAS, 2011, Recife.

NÓVOA, A. Os Professores na Virada do Milênio: do excesso dos discursos à pobreza da prática. Educação e Pesquisa, São Paulo, v. 25, n. 1, p. 11-20, 1999.

O GLOBO. Acervo do Jornal O Globo. In: Caderno Vestibular, Rio de Janeiro, p. 1, 19 set. 1980.

$<$ http://acervo.oglobo.globo.com/busca/?tipoConteudo=pagina\&ordenacaoData=relevancia\&a llwords=testes+de+habilidade+espec\%C3\%ADfica\&anyword=\&noword=\&exactword=\&dec adaSelecionada $=1980 \&$ anoSelecionado $=1980 \&$ mesSelecionado $=9 \&$ diaSelecionado $=19>$.

Acesso em: 27 dez. 2014. 
OLIVEIRA, J. G. Teste de habilidade específica para vestibulandos de Educação Física: permanência ou abolição - um estudo de caso. 1991. 148f. Dissertação (Mestrado em Educação) - Faculdade de Educação, Universidade do Estado do Rio de Janeiro, Rio de Janeiro, 1991.

OLIVEIRA, V. M. Consenso e conflito da Educação Física brasileira. Campinas, SP: Papirus, 1994.

RAWLS, J. Uma teoria da justiça. São Paulo: Martins Fontes, 2000.

RIBEIRO, C. C. Desigualdade de oportunidades e resultados educacionais no Brasil. DADOS - Revista de Ciências Sociais, Rio de Janeiro, v. 54, n. 1, p. 41-87, 2011.

SOARES, C. L. et al. Metodologia do ensino de educação física. São Paulo: Cortez, 1992.

SOARES, C. L. Educação Física: raízes europeias e Brasil. 5. ed. Campinas, SP: Autores Associados, 2012.

SOUZA, J. A Ralé brasileira: quem é e como vive. Belo Horizonte: Editora UFMG, 2011.

TABORDA DE OLIVEIRA, M. A. Políticas Públicas para a Educação Física Escolar no Brasil Durante a Ditadura Militar: Uma só Representação? Perspectiva - Revista do Centro de Ciências da Educação, Florianópolis, v. 21, n. 1, p. 151-178, 2003.

TEIXEIRA, L. G. P. Proposta de uma bateria de testes para avaliação da aptidão física dos candidatos ao curso de Educação Física da Universidade do Amazonas. 1984. 162f. Dissertação (Mestrado em Educação Física) - Escola de Educação Física e Esporte, Universidade de São Paulo, São Paulo, 1984.

ZINN, J. L. Estudo da relação entre testes de aptidão física para admissão ao curso de Educação Física e notas do primeiro ano do curso. Kinesis, Santa Maria, Rio Grande do Sul, v. 4, n. 1, p. 71-95, 1988.

Recebido em: 21/06/2016

Revisado em: 08/08/2016

Aprovado em: 08/08/2016

Endereço para correspondência:

baptista.ufrj@yahoo.com.br

Guilherme Gonçalves Baptista

Universidade Federal do Rio de Janeiro

Avenida Pedro Calmon, 550

Cidade Universitária

21941-901 - Rio de Janeiro, RJ - Brasil 